\title{
Hybrid Classroom using Transparent Interactive Screen-Board (Tisb-Albania) as an Alternative of Faceing Similar Covid-19 Situations
}

\author{
Romeo Teneqexhi ${ }^{1}$, Loreta Kuneshka ${ }^{2 *}$, Marjola Puka ${ }^{3}$ \\ ${ }^{1}$ Ex Director of Distance Education Centre Polytechnic University of Tirana, Albania, Sheshi "Nënë Tereza”, \\ No 4. Tirana, Albania \\ ${ }^{2}$ Lecturer of Statistics Medical University of Tirana, Albania, Rruga e Dibres, Tirana, Albania \\ ${ }^{3}$ Lecturer of Electrotechnics Polytechnic University of Tirana, Albania, Sheshi "Nënë Tereza”, No 4. Tirana, \\ Albania
}

*Corresponding Authors: Loreta Kuneshka, Lecturer of Statistics Medical University of Tirana, Albania ,UniversitetiiMjekësisëiTiranës, Rruga e Dibres, Tirana, Albania

\begin{abstract}
Due to the coronavirus, almost all teachers around the world are teaching through the Internet from home, sitting in a chair, in most cases without even showing the face to the students. Most of the students do not like this. They want the teacher to stand on feet and explain by pointing on his notes on blackboard and make gestures with his hands according to the lesson like they have done historically. Using "tiSb-Albania" system everyone can teach in this way. Moreover, you never turn your back to the students even when you write on the blackboard (which is transparent in this case) during the lecture. You will be all the lesson time face to face with the students watching them. This makes them more focused on the lesson even following it from home. Learning in this form "shortens" the distance between the students and the teacher. "tiSb-Albania" is a plant where several hardware devices and software have been assembled, which serves for doing and recording the lectures in real-time in a very special form. "tiSb-Albania" is the acronym for Transparent Interactive Screen-Board. The beginnings of this system were presented at the 10th $e$ Learning conference organized by IADIS in Madeira 2016(1) and at 3rdInternational Conference on Communication and Management, Athens 2017(2).The system was presented with many new features at the 13th e-Learning conference organized by IADIS in Porto 2019(3), where we announced that work was underway to build the prototype for ordinary users. The COVID19 created an appropriate ground for further experimentation and completion with other necessary features of the system for such situations. We have shared publicly this experience at the 14th e-Learning conference organized by IADIS in Zagreb 2020(4) held virtually by Zoom because of COVID-19 situation. The use of "tiSb-Albania" during the pandemic period as well as other developments in Albanian schools and universities make us draw some conclusions and give some recommendations, we believe valid for the teaching process in extraordinary situations, why not even for normal situations.
\end{abstract}

Keywords: Hybrid Classroom (HC), transparent interactive Screen-board (tiSb-Albania), DTSE (Daily Twice Short Exams), Teach Locally \& Learn Globally (TL\&LG).

\section{Main Portable CONSTRuCTION OF tisb-Albania}

Allhardware devices explained in"Making virtual classrooms of google platform more real using transparent interactive screen-board" ${ }^{(2)}$ are assembled in the construction of first prototype "tiSbAlbania" as shown in Fig 1. This system is now portable and easily implementable in every traditional classroom.
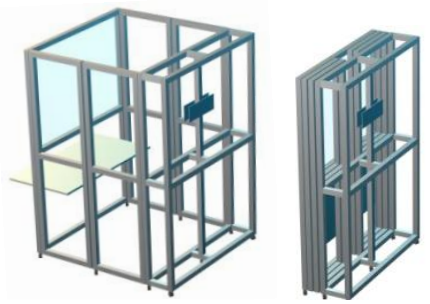
Hybrid Classroom using Transparent Interactive Screen-Board (Tisb-Albania) as an Alternative of Faceing Similar Covid-19 Situations

Fig1. Main construction of tiSb-Alnbaia

\section{Two Experiments With tisb-Albania Before and After Closing Schools Because OF Covid19.}

In Albania, due to an educational reform undertaken in recent years, Distance Education is no longer available. Our work on the "tiSb" project has started before the decision for closing distance education schools. Of course, we never liked this decision but we had nothing to do. In a way we needed to test the prototype in all its parameters with real students. In fact, among other things, we had another strong reason to do an experiment. We hadn't even thought it would come one day and the schools would be closed due to a virus like COVID19. But due to a strong earthquake on November 26 in Albania, the schools were closed for 2 weeks and during this time teaching processstopped at all. We wanted to show the education authorities that we need to be prepared not to interrupted teaching process even though schools may be closed due to natural disasters.

For this we used ananniversary day of opening the first school in Albanian language, March 7, 1887. On March 7, 2020, as a sign of gratitude for my former teachers, I conducted a homage lecture through the system "tiSb-Albania" where most of the students attended it live from home via YouTube while they were logged in "eBeam Scrapbook" platform. The lecture was very successful in all technical parameters. Fig 2.a / b. (Watch this video at: https://www.youtube.com/watch?v=G5gsA gHlyio\&t=856s)

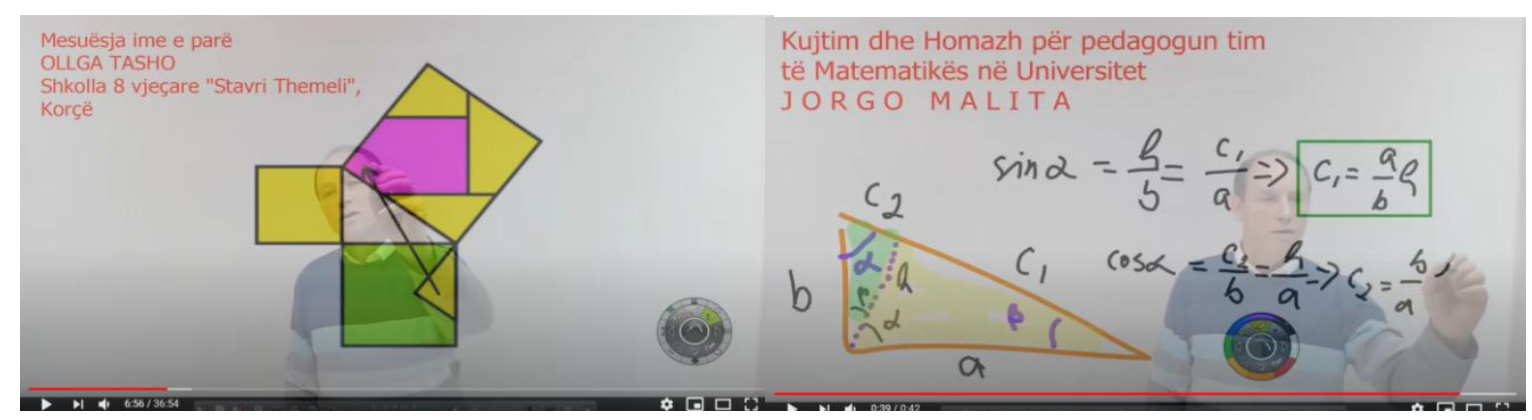

Fig2.a/b. Teaching standing on feet during pandemic time.

Ironically, 2 days later, on March 9, 2020, the Albanian government closed schools after COVID19 was identified in Albania. Covid19 found Albania totally unprepared to continue learning online. Although we notified the education authorities of the existence of the tiSb system, large-scale implementation could not be carried out for many reasons. However, we used and continue to use the "tiSb-Albania" system with great success, perfecting its special features intertwined with existing platforms such as Zoom and Meet.

Immediately after the government closed the schools, we decided to do another big experiment involving as much student as we could, this time to show the educational authorities how the teaching could be organized through the Internet, mainly for primary schools. Through the teaching secretaries, we informed all the students of the Polytechnic University of Tirana to become part of a large virtual classroom to attend a single lecture. We also made the invitation public on FaceBook. To ensure participation in the experiment, we invited a well-known Albanian cartoonist, asking him to make for our lecture a cartoon without title. With this cartoon, through a material stimulus for the participating students, we wanted to test the so-called DTSEideas (we'll talk about that later). The other reason of the cartoon was the treatment of the lecture with humor and optimistic notes very important for the pandemictime.

Well-known Albanian cartoonist BujarKapexhi made a very interesting cartoon which we are publishing (Fig. 3) hoping the cartoon will orient us towards some questions that today concern the whole academic world. About 540 students express the desire to participate in our experiment. The video was transmitted livestreamon You Tube. Some students logged ineBeam Scrapbook. Many other students just watched the livestream video, but they, and not only them, can downloadslides of this lecture any time. All you have to do is connect via eBeam Scrapbook meeting ID 352724420 (slides are on the cloud; ID is on the right up corner of video Fig. 4.a. / 3.b.). Through this experiment we retested "tiSb-Albania" in all technical terms including so-called DTSE (Daily Twice Short 
Exams). It was really a successful experiment. You can watch this video at: https://www.youtube.com /watch?v=PIdK-prQjpE (full version, Albanian language) or at: https://www.youtube.com/watch?v $=1 J y M J y y 5 O F 4$ (short version, music background). After this experiment I personally have used and continue to use "tiSb-Albania" system. I record every lecture and upload it for students in respective Google Classroom. So, my students never lose the lecture even if they have not followed it in real time. For more wehave recorded with this system labs using different software simulators.

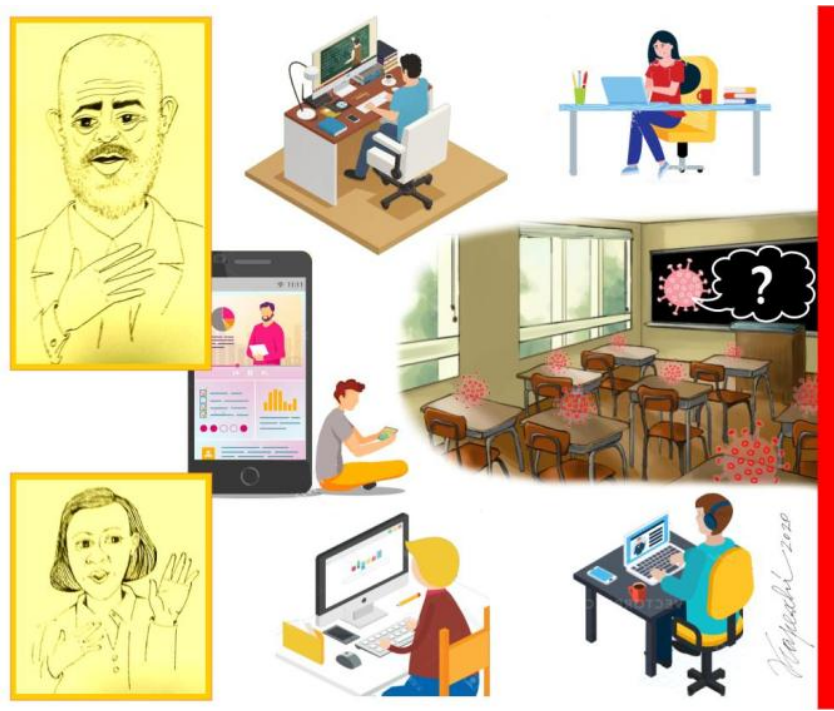

Fig3. Friendly cartoon with Albanian PM and Minister of Education

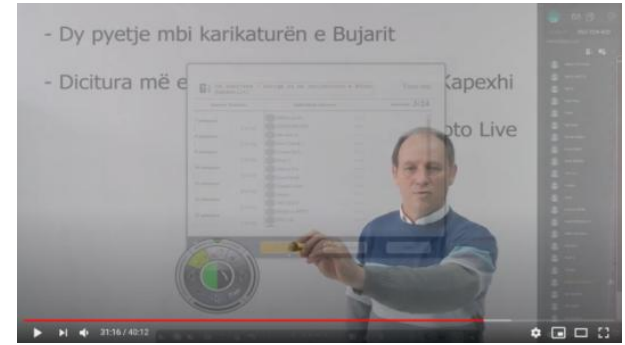

Fig4.a. Daily short exam. Results of $M C Q$

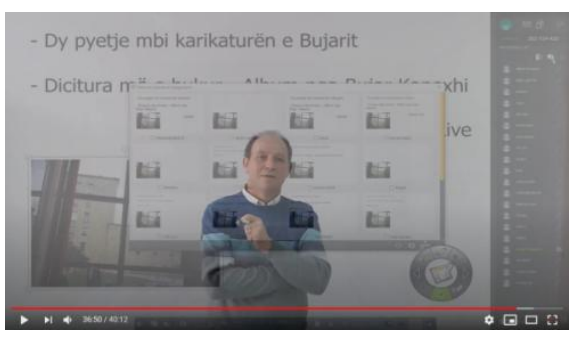

Fig4.b. Individual Question Results

\section{3. tISB-ALBANIA LIVE STREAM IN YOUTUBE VS ZOOM PLATFORM}

During pandemic time we use two different platforms for transmitting livestream, YouTube and Zoom. In both cases we useeBeam Scrapbook software for four very important reasons. First eBeam Scrapbook give us the possibility to have interactive screen-board. Second, we can use prepared slides or create and edit new ones during lecture.Third all these slides students can download after the lecture via eBeam Scrapbook through meeting's ID. Forth and most important is possibility eBeam Scrapbook has to make "short fast exams" during the lecture with MCQ (Multiple Choice Question) or essay type questions. Teacher can save in a Data Base all results of this kind of short exams and use them for final assessment. Zoom platform is very good for video meeting but das not have possibility for MCQ. Zoom annotating tool also does notoffer more than one slide. On the other hand, we have notice most of the students do not want to open the camera for privacy reasons. But some time they just log in Zoom meeting and go away (because no MCQ during lecture). A significate differencebetweenstreaming in YouTube and Zoom platform is the delay in time (some seconds depending on speed of internet) because of streaming. In first case the student has the only possibility to ask the teacher via eBeam Scrapbook chat tool. Any way in both cases recording of lecture is very important.

\section{What About Exams During School Closing Time}

Due to COVID19 schools were closed almost all over the world.Teacherschanged the way of doing lectures, via internet, without knowing when the schools would reopen. Everyone engaged with lectures and almost forgot that the schools could have been closed even at the time when the exams would normally take place. Now all universities have a big challenge ahead: How will the exams be done in case of similar COVID-19 situations. We want to share our experience by suggesting something that sounds unusual "school without traditional exams". How is it possible? We wereconfident that the school would remain closed even during the exam period and doing exams in traditional form would be difficult. So, we organizeteaching hour with two "short exams" before and after the lecture.At the beginning of the lecture, there is a short up to 10minutes exam with MCQ related to the problems of the previous lecture. After the lecture, we do another short exam of up to 10 minutes related to the problems just explained in the lecture. eBeam Scrapbook application offers this option, but it can also be done with Google Form in Google Classroom. This gives the lecturer the 
opportunity to evaluate the student in two very important components, how much he/she has understood from today's lecture and how much he/she understands after reviewing the lecture at home. On the other hand, it is a great advantage that "forces" the student to study systematically as there is no exam at the end of the semester but only DTSE (Daily Twice Short Exams) every day in the lecture.

\section{VIDEO DEMOSTRATION}

We want everybody who reads this article to feel the impression of seeing videos produced by our system (If you are reading electronically this article pressCtrl + Click on this link: https://www.yo utube.com /watch?reload $=9 \& \mathrm{v}=\mathrm{EMtqkCpXDF} 0$, otherwise write the link on browser's URL and press ENTE R)

\section{Conclutions}

- We are of the opinion that the recording of lectures should be done even in normal time. "tiSbAlbania" infrastructure makes it possible. For this, the system must be installed in each lecture classroom and the teacher will do nothing more than usual but just click a button at the beginning and at the end of the lecture. The student should be free to choose to follow the lecture by staying in the same room with the teacher or staying at home or somewhere else online with the teacher.The second version saves the student a lot of time and money by getting a much better service from school. We would like to call this kind of combinationHybridClassroom (HC), some students are in the class, others at home or somewhere else being involved with other tasks that do not require much commitment. Students at home interact with teacher without any difference from the students in the classroom. They can even write on teacher board from home individually or collectively at the same time.

-Recording of lectures and saving them on different platforms of the departments will become a powerful mechanism for improving the quality of teaching and will increase, in a good sense, academic competition, just because of transparency of recorded materials.

- DTSE (Daily Twice Short Exams) every lecture day is an option for substituting some of traditional exams even in normal situation (without pandemic).

- All above are our opinion and conclusions. An extensive survey with students after pandemic would be of great interest for "ACADEMIA POST COVID19".

- Our platform creates the possibility of twining different schools sharing good teachers. It is time to teach locally and learn globally (TL\&LG).

\section{REFERENCES}

[1] Teneqexhi, R. Kuneshka, L. Virtual \& Real Face to Face Teaching. $10^{\text {th }}$ E-LearningMCCSIS 2016, 1-4 July, Madeira, Portugal ISBN: 978-989-8533-51-7, pp. 227-230.

[2] Teneqexhi, R. Kuneshka, L. Transparent Interactive Screen-Board for Virtual \& Real Face to Face Teaching (TIS-B4V\&RF2FT), $3^{\text {rd }}$ International Conference on Communication and Management, Athens 24-27, April 2017

[3] Teneqexhi, R. Kuneshka, L. Making virtual classrooms of Google platform more real using transparent interactive Screen-board (tiSb-Albania). $13^{\text {th }}$ E-LearningMCCSIS 2019, 16-19 July, Porto, Portugal ISBN: 978-989-8533-88-3, pp. 333-336.

[4] TESTING AND USING "tiSb-Albania" (TRANSPARENT INTERACTIVE SCREEN-BOARD) DURING COVID19 / $14^{\text {th }}$ E-Learning MCCSIS 2020, Zagreb, Croatia

Citation: Loreta Kuneshka, et.al., "Hybrid Classroom using Transparent Interactive Screen-Board (TisbAlbania) as an Alternative of Faceing Similar Covid-19 Situations" International Journal of Managerial Studies and Research (IJMSR), vol 9, no. 2, 2021, pp. 18-21. doi: https://doi.org/10.20431/2349-0349.0902003.

Copyright: (1) 2021 Authors. This is an open-access article distributed under the terms of the Creative Commons Attribution License, which permits unrestricted use, distribution, and reproduction in any medium, provided the original author and source are credited. 